\title{
Powder for Dispersion for Injection Dosage Form
}

National Cancer Institute

\section{Source}

National Cancer Institute. Powder for Dispersion for Injection Dosage Form. NCI

Thesaurus. Code C149821.

Solid sterile preparation consisting of one or more powders intended to be dispersed in the specified liquid to obtain a dispersion for injection. 